\title{
IN THE SILENCE OF OTHERS' VOICES
}

\section{Lance Phillips}

1.

Here's my eye against fear, its satellite:

dark mechanic, palmed-communion, react;

the tree flags with piety and ribbon, ants congregate-

react, death's a cathedral, a reliquary,

a meal-.

Bleachers and events constitute a relief,

mothers and little ones. The man, "this is the story

of my life"-all those holes not hearing,

preparing, a truth—, "my goddamn life."

Night alight

with necks, fingers. This-is-December-of-what-lacks.

The paper moment. I remember paper and the sack

of the moment. I remember a bee-swarm in its mauve hive.

- A desolate idea is a hive in lieu of a landscape.-

Parking space scrolled with late rain, soon the squirrel's

deft step. The safer world: space is a task not a body. 
Cardinal-augury flushed from the holly:

berry expanded to bird, a heard lament-

recalcitrant-

needled-leaves-, red from green, sunk

now in the oak. This shirt's a sieve; a radio

faintly disclaiming loss.

The trump

of the world is exile. Trunk and leaves

- brighter nearer the trunk-and avowal of loneliness.

The tree's the road to my place in the body.

3.

You're with me,

who is learning to die, who

violates you in the no-moon

night.

What troubles flame

my escape are coins made light

with age.

Window and cactus do

not lie, wholly, but transact

in elements entirely new. 